\title{
Kemijski sastav 40 sorti jabuke uzgajanih u Gornjem Međimurju
}

\author{
Chemical composition of fruits of 40 apple varieties \\ growing in Gornje Međimurje
}

\section{Miljković}

\section{SAŽETAK}

$\mathrm{Na}$ području Gornjeg Međimurja kultura jabuke ima dugu i slavnu tradiciju. U uzgoju je proširen velik broj domaćih i udomaćenih sorti. Tome su pridonijeli povoljni ekološki uvjeti i širenje sortimenta iz Republičkog voćno-loznog rasadnika Vukanovec. Za oplemenjivanje jabuke potrebno je imati bogatu germoplazmu i poznavati biološka i gospodarska svojstva sorti. U radu se iznose rezultati istraživanja kemijskog sastava i kvalitete plodova 40 sorti. Istraživanja su obuhvatila: suhu tvar, topivu suhu tvar, ukupne šećere, ukupne kiseline, $\mathrm{pH}$ vrijednost i ocjenu kvalitete po Thiault indeksu. Od sorti su obuhvaćene: Ananas reneta, Baumanova reneta, Batulemka, Bijela zimska tafetica, Bjeličnik, Blenheimska, Bobovac, Boskoop, Božićnica, Cox's orange, Crvena jesenska rebrača, Danciška rebrača, Funtača, Golden Delicious, Gravenstein, Harbertova reneta, Jonathan, Kanadska reneta, Kaselska reneta, Krivopeteljka, Landzberška reneta, Laška trdika, London pepping, Ljepocvjetka, Mašanka, Ontario, Ovčji nos, Parker pepping, Ramburka, Red Delicious, Ribston pepping, Siva francuska reneta, Siva jesenska reneta, Starking, Stožerka, Šampanjska reneta, Šarlamovski, Zeleni štetinac, Zlatna zimska parmenka, i Željeznika. U odnosu na: suhu tvar (\%), topivu suhu tvar (\%), ukupne šećere $(\%)$, količinu kiseline $(\mathrm{g} / \mathrm{l})$ i Thiaultov indeks podijeljene su sorte u skupine. Najveću suhu tvar (iznad 17\%) imaju sorte: Blenheimska, Boskoop, Harbertova reneta, Kanadska reneta, Parker pepping, Ribston pepping, Siva francuska reneta i Siva jesenska reneta. Najveću topivu suhu tvar (iznad 15\%) imaju sorte: Baumanova reneta, Harbertova reneta, Kaselska reneta, Landzberška, Bobovac, Ljepocvjetka, Božićnica, Danciška rebrača i Batulemka. Najviše šećera (od 13 - 15\%) sadrže sorte: Blenheimska, Siva jesenska reneta, Siva francuska, Ribston pepping, Parker pepping, Boskoop, Kanadska reneta, Harbertova reneta, Ljepocvjetka, Zlatna zimska parmenka, Golden Delicious i Mašanka. Najviše kiseline (preko $7 \mathrm{~g} / \mathrm{l}$ ) sadrže sorte: Bjeličnik, Ontario, Boskoop, Crvena jesenska rebrača, Kanadska reneta, Laška trdika, Mašanka i Stožerka. Najbolju kvalitetu (Thiault indeks iznad 170) imaju sorte: Ribston pepping, Siva jesenska reneta, Parker pepping, Boskoop, Siva francuska reneta, Kanadska reneta i Crvena jesenska rebrača.

Ključne riječi: jabuka, sorta, plod, kemijski sastav, kvaliteta 


\section{ABSTRACT}

In the area Gornje Međimurje apple culture has a long and famous tradition. Growth has been extended to a large number of domestic and old fashioned varieties. This has contributed to favorable ecological conditions and the expansion of the variety from the Vukanovec republican fruit nursery. For apple breading it is necessary to have rich germplasm and to know the properties of varieties. The paper presents the results of the research of the chemical compositions of 40 varieties, including dry matter, soluble dry matter, total sugar, acidity, $\mathrm{pH}$ value and quality score of the Thiault index. Among varieties are: Ananas Renette, Bauman's Renette, Batulemapfel, Belle Fleur, White Winter Tafetapfel, Yellow Transparent, Blenheimere, Grosse Rheinischer Bohnapfel, Boskoop, Roter Haslinger, Cox's Orange, Red Autumn Kantapfel, Danziger Kantapfel, Funtacha, Golden Delicious, Gravenstein, Harbert's Renette, Jonathan, Renette du Canada, Grosse Kaseler Renette, Rheinischer Krummstiel, Landzberger Renette, Laška Trdika, London Pepping, Steirische Maschanzker, Ontario, Schafsnase, Parker Pepping, Red Delicious, Ribston Pepping, Renette Grise Francaise, Renette Grise Automne, Geflamanter Kardinal, Rambur, Renette de Champagne, Željeznika, Reine de Reinette, Gruner Stettiner, Charlamowsky and Starking. The fruits of the following varieties have the highest content of dry matter (above 17\%): Blenheimere, Boskoop, Harbert's Renette, Renette du Canada, Parker Pepping, Ribston Pepping, Renette Grise Francaise, Renette Grise Automne. The fruits of the following varieties have the highest soluble dry matter (above 15\%): Baunab's Renette, Harbert's Renette, Grosse Kaseler Renette, Landzberger Renette, Roter Haslinger, Danziger Kantapfel, and Batulemapfel. Highest amount of sugar (13 - 15\%) contain fruits of varieties: Blenheimere, Renette Grise Automne, Ribston Pepping, Parker Pepping, Boskoop, Renette du Canada, Harbert's Renette, Belle Fleur, Reine de Reinette, Golden Delicious, and Steirische Maschanzker. Most acids (over $7 \mathrm{~g} / \mathrm{l}$ ) contain varieties: Yellow Transparent, Boskoop, Red Autumn Kantapfel, Renette du Canada, Laška Trdika, Steirische Maschanzker and Geflamanter Kardinal. The varieties that have the best quality (Thiault index above 170) are: Ribston Pepping, Renette Grise d'Automne, Parker Pepping, Boskoop, Renette Grise Francaise, and Renette du Canada.

Keywords: apple, variety, fruit, chemical composition, quality

\section{UVOD}

Na području Gornjeg Međimurja postoje vrlo povoljni uvjeti za proizvodnju kvalitetnih plodova jabuke. Uzgoj jabuke proširen je na blagim padinama brežuljaka. U uzgoju dolazi velik broj sorti. Proširenosti velikog broja sorti doprinio je Republikanski voćno-lozni rasadnik Vukanovec. Godine 1957. moje prvo radno mjesto, poslije diplome na Poljoprivredno-šumarskom fakultetu u Zagrebu, bilo je u Poljoprivrednoj stanici C̆akovec, gdje sam postavljen za referenta za voćarstvo, vinogradarstvo, vinarstvo i pedologiju. Najprije sam počeo pedološka istraživanja u voćnjacima i vinogradima, a potom istraživanje kemijskog sastava plodova velikog broja sorata. U to vrijeme otkup jabuka bio je 
organiziran preko Voćarsko-vinogradarskog zadružnog saveza u Čakovcu. Velike količine otkupljenih jabuka izvozile su se u Njemačku. Kako je u to vrijeme na jabukama bio proširen karantenski štetnik kalifornijska štitasta uš, jabuke su u vagonima prolazile, prije izvoza, cijanizaciju u Pragerskom (Slovenija). Pregledom voćnjaka ustanovio sam da je u uzgoju velik broj kvalitetnih sorti jabuke na području: Lopatinca, Vukanovca, Štrigove, Preseke, Željezne Gore, Tupkovca i Stanetinec brega. Malo je bilo voćnjaka u kojima se uzgajala samo jabuka. Jabuka je uglavnom uzgajana u konsocijaciji sa drugim voćkama. Pretežno su to mješoviti voćnjaci ili su to pojedinačna stabla uzgajana u rasutom stanju. Sorte su uzgajane na podlozi sjemenjaka šumske jabuke (Malus sylvestris), a od uzgojnih oblika su najčešće popravljena piramida i popravljena vaza. Početkom pedesetih godina od strane Zavoda za voćarstvo na čelu $\mathrm{s}$ dipl. ing. Otom Bohutinskim i dr. sc. Ivom Modrićem podignuti su na području gornjeg Međimurja prvi pokusni voćnjaci, s novim gospodarski vrijednim sortama na vegetativnim podlogama. U tim voćnjacima postizani su visoki prirodi kvalitetnih plodova. Uspješno sam surađivao s prijateljem dr. sc. Modrićem i proveo pedološka istraživanja u pokusnim voćnjacima u Vukanovcu, Željeznoj Gori i Tupkovcu. Rezultate osmogodišnjih istraživanja rasta i istraživanja: vegetativne razvijenosti, fenologije cvatnje, početka rodnosti, priroda, otpornosti prema niskim temperaturama i druge važne podatke o biološkim i gospodarskim osobinama sorata na vegetativnim podlogama objavio je 1961. godine dr. sc. Ivo Modrić u knjizi: „Odnosi sorte i podloge jabuka“. Zbog povoljnih ekoloških uvjeta za uzgoj jabuke i postizanje visoke kakvoće plodova. Gornje Međimurje predstavlja jedinstveno voćarsko područje, u kojem je jabuka zauzela vodeće mjesto među svim ostalim voćnim vrstama, pa se može usporediti sa Meranom u Tirolu. Da pridonesem boljem poznavanju bogatog genetskog resursa uzgajanih sorti odlučio sam istražiti kemijski sastav i ocijeniti kvalitetu njihovih plodova.

\section{OBJEKT ISTRAŽIVANJA I METODE RADA}

Uzorci plodova za kemijsku analizu uzimani su sa dobro razvijenih i prosječno rodnih stabala šireg područja Gornjeg Međimurja, nadmorske visine od 190 do $220 \mathrm{~m}$. Prema Thornthwaitovoj klasifikaciji to je područje humidne klime. Prema Köpprnovoj klasifikaciji to je područje označeno cfwba. Tlo je uglavnom srednje duboki obronačni pseudoglej na diluvijalnoj ilovini pleistocena. Za analizu kemijskog sastava plodova primijenjeni su aktualni klasični postupci u vrijeme obavljenih istraživanja. Za kemijsku analizu u 1957. i 1958. godini, sa istih, označenih stabala, uzimana su za svaku sortu po tri prosječna uzorka od po jedan kilogram plodova u vrijeme zrelosti za potrošnju. 
Istraživanja su obuhvatila: suhu tvar. topivu suhu tvar, ukupne šećere, ukupne kiseline, $\mathrm{pH}$ vrijednost i ocjenu kvalitete plodova prema Thiault indeksu. Plodovi su samljeveni u stroju, a zatim protrljani u tarioniku, da se čestice bolje usine i dobije što homogenija masa. Prije očitanja refraktometarske vrijednosti protisnut je sok iz voćne mase kroz tanki sloj vate, da se odstrane krute čestice. Nakon toga topiva suha tvar je određena sa Zeissovim refraktometrom. Iz istog uzorka određeni su ukupni šećeri gravimetrijski Fehlingovim otopinama. Količina ukupnih kiselina određena titracijom $\mathrm{s} \mathrm{n} / 10 \mathrm{NaOH}$, a $\mathrm{pH}$ vrijednost je utvrđena potenciometrijski. Rezultati su iskazani kao srednje vrijednosti dvogodišnjih istraživanja.

\section{REZULTATI ISTRAŽIVANJA}

Rezultati istraživanja kemijskog sastava (suha tvar, topiva suha tvar, ukupni šećeri, ukupne kiseline, $\mathrm{pH}$ vrijednost) i kvalitete plodova 40 sorti jabuka iskazani su na tablici 1.

Tablica 1. Kemijski sastav plodova 40 sorti jabuke

Table 1 Chemical composition of fruits of $\mathbf{4 0}$ apple varieties

\begin{tabular}{|l|c|c|c|c|c|c|}
\hline \multicolumn{1}{|c|}{$\begin{array}{c}\text { Sorta } \\
\text { Variety }\end{array}$} & $\begin{array}{c}\text { Suha tvar } \\
\text { Dry } \\
\text { matter } \\
\%\end{array}$ & $\begin{array}{c}\text { Topiva } \\
\text { suha tvar } \\
\text { Soluble dry } \\
\text { matter \% }\end{array}$ & $\begin{array}{c}\text { Ukupni } \\
\text { šćeri } \\
\text { Total sugar } \\
\%\end{array}$ & $\begin{array}{c}\text { Kiseline } \\
\text { Acidity } \\
\mathrm{g} / 1\end{array}$ & $\mathrm{pH}$ & $\begin{array}{c}\text { Kvaliteta } \\
\text { Quality } \\
\text { Thiault } \\
\text { index }\end{array}$ \\
\hline $\begin{array}{l}\text { Ananas reneta - } \\
\text { Ananas Renette }\end{array}$ & 12,40 & 12,1 & 9,60 & 4,49 & 3,49 & 113 \\
\hline $\begin{array}{l}\text { Baumanova reneta - } \\
\text { Bauman's Renette }\end{array}$ & 15,96 & 15,4 & 12,90 & 4,64 & 4,13 & 143 \\
\hline Batulemka - Batulemapfel & 14,80 & 14,0 & 11,50 & 5,40 & 3,55 & 143 \\
\hline $\begin{array}{l}\text { Bijela zimska fatetica - } \\
\text { White Winter Tafetapfel }\end{array}$ & 13,92 & 13,2 & 10,75 & 5,03 & 3,52 & 127 \\
\hline $\begin{array}{l}\text { Bjeličnik - } \\
\text { Yellow Transparent }\end{array}$ & 12,24 & 11,0 & 8,39 & 9,10 & 3,31 & 136 \\
\hline Blenheimska - Blenheimer & 17,45 & 17,1 & 14,22 & 4,95 & 4,10 & 164 \\
\hline $\begin{array}{l}\text { Bobovac - } \\
\text { Grosse Rheinischer Bohnapfel }\end{array}$ & 15,5 & 14,8 & 12,06 & 4,50 & 4,00 & 137 \\
\hline $\begin{array}{l}\text { Boskoop - } \\
\text { La Bell de Boskoop }\end{array}$ & 17,82 & 17,4 & 13,81 & 7,71 & 3,94 & 177 \\
\hline Božićnica - Roter Haslinger & 15,00 & 14,4 & 11,38 & 5,67 & 3,38 & 141 \\
\hline Cox's orange & 14,10 & 13,0 & 12,20 & 4,31 & 3,42 & 132 \\
\hline $\begin{array}{l}\text { Crvena jesenska rebrača - } \\
\text { Red Autumn Kantapfel }\end{array}$ & 13,57 & 13,3 & 11,08 & 7,67 & 2,92 & 158 \\
\hline $\begin{array}{l}\text { Crveni delicious - } \\
\text { Red Delicious }\end{array}$ & 12,55 & 12,4 & 11,60 & 2,91 & 3,86 & 122 \\
\hline
\end{tabular}


I. Miljković: Kemijski sastav 40 sorti jabuke uzgajanih u Gornjem Međimurju

\begin{tabular}{|c|c|c|c|c|c|c|}
\hline $\begin{array}{l}\text { Danciška - } \\
\text { Danziger Kantapfel }\end{array}$ & 14,65 & 14,1 & 12,23 & 5,92 & 3,26 & 149 \\
\hline Funtača - Funtacha & 14,24 & 13,2 & 11,00 & 4,90 & 3,84 & 138 \\
\hline Golden Delicious & 13,65 & 134 & 13,20 & 5,20 & 3,92 & 154 \\
\hline Grafenštajn - Gravenstein & 12,50 & 12,0 & 10,65 & 6,53 & 3,32 & 135 \\
\hline $\begin{array}{l}\text { Harbertova reneta - } \\
\text { Harbert's Renette }\end{array}$ & 17,56 & 15,4 & 13,22 & 3,71 & 3,21 & 148 \\
\hline Jonathan & 14,21 & 13,0 & 12,20 & 6,30 & 3,31 & 152 \\
\hline $\begin{array}{l}\text { Kanadska reneta - } \\
\text { Renette du Canada }\end{array}$ & 17,35 & 17,2 & 13,65 & 7,00 & 3,95 & 173 \\
\hline $\begin{array}{l}\text { Kaselska reneta - } \\
\text { Grosse Caseler Renette }\end{array}$ & 15,43 & 15,2 & 12,59 & 4,64 & 4,25 & 154 \\
\hline $\begin{array}{l}\text { Krivopeteljka - } \\
\text { Reinische Krummstiel }\end{array}$ & 14,07 & 13,0 & 11,18 & 6,27 & 5,88 & 140 \\
\hline $\begin{array}{l}\text { Landsberška reneta - } \\
\text { Landsberger Renette }\end{array}$ & 15,40 & 15,0 & 12,37 & 4,56 & 3,30 & 142 \\
\hline Laška trdika & 12,90 & 12,6 & 9,41 & 7,43 & 3,02 & 130 \\
\hline $\begin{array}{l}\text { London pepping - } \\
\text { London Pepping }\end{array}$ & 12,37 & 12,1 & 11,16 & 4,89 & 4,03 & 135 \\
\hline Ljepocvjetka - Belle Fleur & 15,51 & 14,5 & 13,65 & 4,80 & 4,46 & 156 \\
\hline $\begin{array}{l}\text { Mašanka - } \\
\text { Steirische Maschanzker }\end{array}$ & 16,95 & 16,3 & 13,38 & 7,03 & 3,98 & 168 \\
\hline Ovčji nos - Schafsnase & 13,88 & 13,0 & 11,61 & 2,56 & 3,54 & 110 \\
\hline Ontario & 12,63 & 12,2 & 9,61 & 6,31 & 3,88 & 125 \\
\hline $\begin{array}{l}\text { Parker pepping - } \\
\text { Parker Pepping }\end{array}$ & 17,50 & 16,5 & 13,75 & 6,40 & 3,18 & 178 \\
\hline Ramburka - Rambur & 14,15 & 13,1 & 10,12 & 3,76 & 4,35 & 113 \\
\hline $\begin{array}{l}\text { Ribston pepping - } \\
\text { Ribston Pepping }\end{array}$ & 18,04 & 16,9 & 15,64 & 5,87 & 3,57 & 183 \\
\hline $\begin{array}{l}\text { Siva francuska reneta - } \\
\text { Renette Grise Francaise }\end{array}$ & 17,32 & 16,0 & 14,91 & 6,65 & 3,64 & 175 \\
\hline $\begin{array}{l}\text { Siva jesenska reneta - } \\
\text { Renette Grise Automne }\end{array}$ & 18,30 & 17,6 & 15,44 & 5,54 & 3,90 & 180 \\
\hline Starking & 14,55 & 13,9 & 11,89 & 1,80 & 4,18 & 120 \\
\hline $\begin{array}{l}\text { Stožerka - } \\
\text { Geflamater Kardinal }\end{array}$ & 13,03 & 12,0 & 10,91 & 7,75 & 3,03 & 147 \\
\hline $\begin{array}{l}\text { Šampanjska reneta - } \\
\text { Renette de Champagne }\end{array}$ & 13,30 & 12,9 & 10,76 & 6,42 & 4,64 & 138 \\
\hline Šarlamovski - Charlamovsky & 13,30 & 12,9 & 10,76 & 6,42 & 4,63 & 133 \\
\hline $\begin{array}{l}\text { Zeleni štetinac - } \\
\text { Gruner Stettiner }\end{array}$ & 12,24 & 11,8 & 9,14 & 6,03 & 3,26 & 117 \\
\hline $\begin{array}{l}\text { Zlatna zimska parmenka - } \\
\text { Reine de Renette }\end{array}$ & 16,88 & 14,8 & 13,30 & 6,50 & 3,53 & 161 \\
\hline Željeznika & 13,30 & 12,3 & 10,61 & 3,42 & 4,19 & 115 \\
\hline
\end{tabular}


$\mathrm{Na}$ tablici vidimo da postoje dosta velike razlike između pojedinih sorti $\mathrm{u}$ postotku suhe tvari, topive suhe tvari, količini ukupnih šećera, g/l kiseline, $\mathrm{pH}$ vrijednosti i kvaliteti plodva. U povoljnim ekološkim uvjetima Gornjeg Međimurja velik broj sorti ima visoku suhu tvar, topivu suhu tvar, količinu šećera i kiseline. Interesantno je istaći da je odnos između suhe tvari i topive suhe tvari, zatim između topive suhe tvari i količine šećera vrlo povoljan $u$ većine sorti. $U$ narednim tablicama razvrstane su sorte, radi boljeg pregleda, $u$ skupine prema sadržaju: suhe tvari, topive suhe tvari, ukupnih šećera, ukupne kiseline, $\mathrm{pH}$ vrijednosti i kvaliteti prema Thiault indeksu. Na tablici 2 razvrstane su sorte prema zastupljenosti suhe tvari.

Tablica 2. Podjela sorti u skupine prema količini suhe tvari u \%

Table 2 Division of varieties into groups according to the amount of dry matter in \%

\begin{tabular}{|c|c|c|c|}
\hline Sorta & $\%$ & Sorta & $\%$ \\
\hline \multicolumn{2}{|c|}{ iznad $17 \%$ (above 17\%) } & \multicolumn{2}{|c|}{ od 15 do $17 \%$ (from 15 to $17 \%$ ) } \\
\hline Blenheimska & 17,45 & Baumanova reneta & 15,96 \\
\hline Boskoop & 17,82 & Ljepocvjetka & 15,51 \\
\hline Harbertova reneta & 17,56 & Bobovac & 15,05 \\
\hline Kanadska reneta & 17,35 & Božićnica & 15,00 \\
\hline Parker pepping & 17,50 & Kaselska reneta & 15,43 \\
\hline Ribston pepping & 18,04 & Landsberška reneta & 15,40 \\
\hline Siva francuska reneta & 17,32 & Mašanka & 16,95 \\
\hline Siva jesenska reneta & 18,30 & Zlatna zimska parmenka & 16,88 \\
\hline \multicolumn{4}{|c|}{ od 13 do $15 \%$ (from 13 to $15 \%$ ) } \\
\hline Batulemka & 14,80 & Crvena jesenska rebrača & 13,57 \\
\hline Cox's orange & 14,10 & Bijela zimska tafetica & 13,92 \\
\hline Danciška rebrača & 14,65 & Ovčji nos & 13,88 \\
\hline Funtača & 14,24 & Šampanjska reneta & 13,30 \\
\hline Jonathan & 14,21 & Stožerka & 13,03 \\
\hline Krivopeteljka & 14,07 & Golden Delicious & 13,65 \\
\hline Ramburka & 14,15 & Željeznika & 13,30 \\
\hline Starking & 14,55 & Šarlamovsy & 13,30 \\
\hline \multicolumn{4}{|c|}{ ispod $13 \%$ (below 13\%) } \\
\hline Ananas reneta & 12,40 & London pepping & 12,37 \\
\hline Red Delicious & 12,55 & Ontario & 12,63 \\
\hline Gravenstein & 12,50 & Zeleni štetinac & 12,24 \\
\hline Laška trdika & 12,90 & Bjeličnik & 11,24 \\
\hline
\end{tabular}


Na tablici 3. iznesena je podjela sorti ovisno o količini topive suhe tvari.

Tablica 3 Podjela sorti u skupine prema količini topive suhe tvari u \%

Table 3 Division of varieties into groups according to the amount of soluble dry matter in \%

\begin{tabular}{|l|c|l|c|}
\hline \multicolumn{1}{|c|}{ Sorta } & $\%$ & \multicolumn{1}{c|}{ Sorta } & $\%$ \\
\hline \multicolumn{3}{|c|}{ iznad 17\% (above 17\%) } & \multicolumn{2}{c|}{ od 15 do 17 \% (from 15 to 17\%) } \\
\hline Siva jesenska reneta & 17,6 & Ribston pepping & 16,9 \\
\hline Boskop & 17,4 & Parker pepping & 16,5 \\
\hline Kanadska reneta & 17,2 & Mašanka & 16,3 \\
\hline Blenheimska & 17,1 & Siva francuska reneta & 16,0 \\
\hline \multicolumn{4}{|c|}{ od 13 do 15 \% (from 13 to 15\%) } \\
\hline Baumanova reneta & 15,4 & Starking & 13,9 \\
\hline Harbertova reneta & 15,4 & Zlatna zimska parmenka & 14,8 \\
\hline Kaselska reneta & 15,2 & Crvena jesenska rebrača & 13,3 \\
\hline Landsberška & 15,0 & Bijela zimska tafetica & 13,2 \\
\hline Bobovac & 14,8 & Funtača & 13,2 \\
\hline Ljepocvjetka & 14,5 & Cox's orange & 13,0 \\
\hline Bižićnica & 14,4 & Krivopeteljka & 13,0 \\
\hline Danciška rebrača & 14,1 & Jonathan & 13,0 \\
\hline Batulemka & 14,0 & Ovčji nos & 13,0 \\
\hline Golden Delicious & 13,4 & Ramburka & 13,1 \\
\hline \multicolumn{5}{|c|}{ ispod 13 \% (below 13\%) } \\
\hline Šampanjska reneta & 12,9 & Ananas reneta & 12,3 \\
\hline Šarlamovsky & 12,9 & London pepping & 12,1 \\
\hline Laška trdika & 12,6 & Gravenstein & 12,0 \\
\hline Red Delicious & 12,4 & Stožerka & 12,0 \\
\hline Željeznika & 12,3 & Bjeličnik & 11,0 \\
\hline Ontario & 12,4 & Zeleni štetinac & 11,8 \\
\hline
\end{tabular}


Na tablici 4. razvrstane su sorte u skupine ovisno o količini ukupnih šećera.

Tablica 4. Podjela sorti u skupine prema količini ukupnih šećera u \%

Table 4 Division of varieties into groups according to the amount total sugar in \%

\begin{tabular}{|c|c|c|c|}
\hline Sorta & $\%$ & Sorta & $\%$ \\
\hline \multicolumn{4}{|c|}{ od 13 do $15 \%$ (from 13 to $15 \%$ ) } \\
\hline Blenheimska & 14,22 & Parker pepping & 13,75 \\
\hline Ljepocvjetka & 13,65 & Ribston pepping & 15,64 \\
\hline Boskoop & 13,81 & Siva jesenska reneta & 15,44 \\
\hline Harbertova reneta & 13,22 & Siva francuska reneta & 14,91 \\
\hline Kanadska reneta & 13,69 & Golden Delicious & 13,20 \\
\hline Mašanka & 13,38 & Zlatna zimska parmenka & 13,30 \\
\hline \multicolumn{4}{|c|}{ od 12 do $13 \%$ (from 12 to $13 \%)$} \\
\hline Baumanova reneta & 12,90 & Jonathan & 12,20 \\
\hline Bobovac & 12,06 & Kaselska reneta & 12,59 \\
\hline Cox's orange & 12,20 & Landberška & 12,37 \\
\hline Danciška rebrača & 12,223 & & \\
\hline \multicolumn{4}{|c|}{ od 10 do $12 \%$ (from 10 to $12 \%$ ) } \\
\hline Batulemka & 11,50 & Gravenstein & 10,65 \\
\hline Božićnica & 11,38 & Ramburka & 10,12 \\
\hline Crvena jesenska rebrača & 11,08 & Šampanjska reneta & 10,76 \\
\hline Red Delicious & 11,60 & Stožerka & 10,91 \\
\hline Funtača & 11,00 & Željeznika & 10,61 \\
\hline Krivopeteljka & 11,18 & Šarlamovsky & 10,76 \\
\hline SratkingLondon pepping & 11,16 & Starking & 11,89 \\
\hline Ovčji nos & 10,16 & Bijela zimska tafetica & 10,75 \\
\hline \multicolumn{4}{|c|}{ ispod $10 \%$ (below $10 \%$ ) } \\
\hline Ananas reneta & 9,60 & Laška trdika & 9,41 \\
\hline Bjeličnik & 8,35 & Zeleni štetinac & 9,14 \\
\hline
\end{tabular}


$\mathrm{Na}$ tablici 5. podijeljene su sorte po skupina ovisno o sadržaju kiseline u plodovima.

\section{Tablica 5. Podjela sorti u skupine po količini kiseline u g/l}

Table 5 Division of varieties into groups according to the amount of acid in $\mathrm{g} / \mathrm{l}$

\begin{tabular}{|c|c|c|c|}
\hline Sorta & $\mathrm{g} / 1$ & Sorta & $\mathrm{g} / 1$ \\
\hline \multicolumn{4}{|c|}{ preko $7 \mathrm{~g} / 1$ (above $7 \mathrm{~g} / \mathrm{l})$} \\
\hline Boskoop & 7,71 & Mašanka & 7,03 \\
\hline Crvena jesenska rebrača & 7,67 & Stožerka & 7,75 \\
\hline Kanadska reneta & 7,00 & Bjeličnik & 9,10 \\
\hline Laška trdika & 7,43 & & \\
\hline \multicolumn{4}{|c|}{ od 6 do $7 \mathrm{~g} / 1$ (from 6 to $7 \mathrm{~g} / \mathrm{l})$} \\
\hline Jonathan & 6,30 & Zeleni štetinac & 6,03 \\
\hline Krivopeteljka & 6,27 & Zlatna zimska parmenka & 6,50 \\
\hline Ontario & 6,31 & Šarlamovsky & 6,42 \\
\hline Parker pepping & 6,40 & Gravenstein & 6,50 \\
\hline Šampanjka & 6,42 & & \\
\hline \multicolumn{4}{|c|}{ od 5 do $6 \mathrm{~g} / 1$ (from 5 to $6 \mathrm{~g} / \mathrm{l})$} \\
\hline Batulemka & 5,40 & Ribston pepping & 5,64 \\
\hline Božićnica & 5,67 & Siva jesenska reneta & 5,54 \\
\hline Danciška rebrača & 5,92 & Siva francuska reneta & 5,65 \\
\hline Bijela zimska tafetica & 5,03 & Golden Delicious & 5,20 \\
\hline \multicolumn{4}{|c|}{ od 4 do $5 \mathrm{~g} / 1$ (from 4 to $5 \mathrm{~g} / \mathrm{l})$} \\
\hline Ananas reneta & 4,49 & Cox's orange & 4,31 \\
\hline Baumanova reneta & 4,64 & Funtača & 4,90 \\
\hline Ljepocvjetka & 4,80 & Kaselska reneta & 4,64 \\
\hline Blenheimska & 4,92 & Landsberška & 4,58 \\
\hline Bobovac & 4,50 & London pepping & 4,89 \\
\hline \multicolumn{4}{|c|}{ ispod $4 \mathrm{~g} / 1$ (below $4 \mathrm{~g} / \mathrm{l})$} \\
\hline Starking & 1,80 & Harbertova reneta & 3,71 \\
\hline Ovčji nos & 2,56 & Ramburka & 3,76 \\
\hline Red Delicious & 2,91 & Željeznika & 3,42 \\
\hline
\end{tabular}


Na tablici 6. predočene su vrijednosti Thiault indeksa za kvalitetu plodova.

\section{Tablica 6. Podjela sorti u skupine prema Thiault indeksu}

Table 6 Division of varieties into groups according to Thiault index

\begin{tabular}{|c|c|c|c|}
\hline Sorta & & Sorta & \\
\hline \multicolumn{4}{|c|}{ preko 170 (above 170) } \\
\hline Ribston pepping & 183 & Boskoop & 177 \\
\hline Siva jesenska reneta & 180 & Siva francuska reneta & 175 \\
\hline Parker pepping & 178 & Kanadska reneta & 173 \\
\hline \multicolumn{4}{|c|}{ od 150 do 170 (from 150 to 170 ) } \\
\hline Blenheimska & 164 & Crvena jesenska rebrača & 158 \\
\hline Mašanka & 168 & Jonathan & 152 \\
\hline Ljepocvjetka & 156 & Kaselska reneta & 154 \\
\hline Zlatna zimska parmenka & 161 & Golden Delicious & 154 \\
\hline \multicolumn{4}{|c|}{ od 140 do 150 (from 140 to 150 ) } \\
\hline Baumanova reneta & 143 & Harbertova reneta & 148 \\
\hline Batulemka & 143 & Krivopeteljka & 140 \\
\hline Božićnica & 141 & Landsberška & 142 \\
\hline Danciška rebrača & 149 & Stožerka & 147 \\
\hline \multicolumn{4}{|c|}{ od 130 do 140 (from 130 to 140 ) } \\
\hline Blenheimska & 136 & London pepping & 135 \\
\hline Bobove & 137 & Šampanjska reneta & 138 \\
\hline Cox's orange & 132 & Šarlamovski & 133 \\
\hline Gravenstein & 132 & Bijela zimska tafetica & 136 \\
\hline Laška trdika & 130 & & \\
\hline \multicolumn{4}{|c|}{ ispod 130 (below 130) } \\
\hline Ananas reneta & 113 & Red Delicious & 122 \\
\hline Ovčji nos & 110 & Ramburka & 113 \\
\hline Starking & 120 & Zeleni štetinac & 117 \\
\hline Željeznika & 115 & Funtača & 113 \\
\hline
\end{tabular}




\section{RASPRAVA I ZAKLJUČCI}

Ustanovljena je podudarnost rezultata istraživanja odnosa između topive suhe tvari i količine šećera, sa podatcima što ih navodi K. Štampar (1952.). Na kemijski sastav ploda jabuke, pored sortnog obilježja, utječe više čimbenika (Fasllahi et al. 1985.). Sansavini et al. (2008.) su na osnovi dvogodišnji istraživanja utjecaja 11 vegetativnih podloga na fizičko kemijska svojstva ploda sorte Golden Delicious, ustanovili da plodovi sa stabala uzgajanih na: Marc 9, M 26, i Pajam sadrže više šećera nego na ostalih 8 podloga. Više kiseline sadržavali su plodovi pod utjecajem podloga: EMLA 9, T 337, Pajam 2 i Jork 9. Najbolju kvalitetu, prema Thiault indeksu postigli su plodovi na podlozi Marc 9, Istraživanjem kemijskog sastava plodova 7 sorti jabuke na 6 vegetativnih podloga Miljković (2018.) nije utvrdio signifikantne razlike u količini šećera i kiseline pod utjecajem podloge. Velik utjecaj na kemijski sastav i kvalitetu plodova odražavaju ekološki uvjeti, a posebno klimatske prilike (Asirelli i Sansavini 1997., Meredifi et al. 1989., Corelli Grappadelli et al. 1999., Miljković 2018.). Talijanski istraživači ističu da plodovi iste sorte jabuke u nizini sadrže i do $1,5 \%$ manje šećera od plodova proizvedenih na povišenim brežuljkastim položajima. Ovo se tumači time što su noći na povišenim položajima hladnije pa je noću smanjeno disanje i utrošak asimilata na disanje, dok su noći u nizini toplije pa je disanje veće, a time i utrošak šećera veći. U literaturi se navodi da ekscesivna gnojidba dušikom i kalijem nepovoljno utječe na kvalitetu i skladišnu sposobnost plodova (Gorini F., 1986., Meredith et al. 1989., Foroyth i Webster 1971., Comai et al. 1995., Noe et al. 1997.). Kvalitetu ploda sorti jabuke, pored kemijskog sastav, najbolje se može ocijeniti organoleptički jer se na taj način obuhvaća više međusobno povezanih svojstava (Watada et al 1980., Steiner et al. 2000., Höller i Guerra 2009., i drugi). Potrošači kvalitetu ploda ocjenjuju organoleptički. Spomenimo samo neke razlike vezane uz okus potrošača Prema istraživanjima okusa potrošača (Höller i Guerra 2009.) po jednom projektu ISAFRUIT u kojem je sudjelovalo 200 istraživača iz 60 instituta, i pod projektu "Newfruit" u kojem su sudjelovali potrošači iz: Njemačke, Poljske, Francuske Španjolske i Nizozemske ustanovljeno je da oko dvije trećine potrošača Europe preferira slatke jabuke, a trećina preferira kiselkaste. Od sjevernih zemalja u Njemačkoj su bolje ocijenjene jabuke sa više kiseline. Tako $58 \%$ njemačkih potrošača preferira kiselkastije jabuke, kao što su primjerice sorte: Kanzi, Ligol, Junami, Jonagold i Pink Lady, a 42\% slatke jabuke kao što su Red Delicious, Fuji i druge. Slatke jabuke preferiraju potrošači u slijedećim državama: Švicarska $(76 \%)$, Španjolska (74\%), Poljska (72\%), Nizozemska (69\%) i Italija (63\%). Među sortama sa slatkim plodovima, malo kiseline ističu se sorte iz sortne skupine 
Red Delicious. Kako vidimo jabuke $\mathrm{s}$ manje kiseline najmanje preferiraju Švicarci (26\%) i Nizozemci (31\%). U zemljama južnog Sredozemlja, a također i u južnim predjelima Italije, a isto tako u nas u Dalmaciji potrošači preferiraju slatke jabuke. Nasuprot tome potrošači Zagreba preferiraju više slatkokiselkaste jabuke, osvježavajućeg okusa. Kod organoleptičke ocjene vodi se računa o više svojstava, a ne samo o šećerima i kiselini. Poznata je latinska izreka „De gustibus non est disputandum“ (O ukusu se ne raspravlja). Ipak je vrlo važno poznavati ukus potrošača pojedinih tržišta. U radu je ocjena kvalitete obavljena prema Thiault indeksu. Thiault indeks za ocjenu kvalitete plodova vodi računa o odnosu između šećera i kiseline. Zato ističemo da za sorte čiji plodovi sadrže manje kiseline nije objektivna ocjena kvalitete po Thiault indeksu, jer veliki broj potrošaka preferira i slatke jabuke.

$\mathrm{Na}$ temelju provedenih istraživanja mogu se izvesti slijedeći zaključci.

U ekološkim uvjetima Gornjeg Međimurja plodovi istraživanih sorti postižu dobru kvalitetu ovisno o svojim genetskim specifičnostima.

- Najveću suhu tvar (iznad 17\%), imaju plodovi sorti: Blenheimska, Boskoop, Harbertova reneta, Kanadska reneta, Parker pepping, Ribston pepping, Siva francuska reneta i Siva jesenska reneta.

- Najveću topivu suhu tvar (iznad 15\% ) imaju plodovi sorti: Siva jesenska reneta, Boskoop, Kanadska reneta, Blenheimska, Ribston pepping, Parker pepping, Mašanka i Siva jesenska reneta.

- Najveću količinu šećera (od 13 do 15\%) sadrže plodovi sorti: Ribston pepping, Parker Pepping, Siva francuska reneta, Siva jesenska reneta, Blenheimska, Boskoop, Kanadska reneta, Ljepocvjetka, Harbertova reneta, Zlatna zimska parmenka, Golden Delicious i Mašanka.

- Najveća količina kiseline (iznad $7 \mathrm{~g} / \mathrm{l}$ ) utvrđena je u plodovima sorti: Boskoop, Crvena jesenska rebrača, Mašanka, Stožerka, Kanadska reneta, Laška trdika i Bjeličnik

- Najbolju kvalitetu ploda prema Thiault indeksu (iznad 170) imaju sorte: Ribston pepping, Siva jesenska reneta, Parker pepping, Boskoop, Kanadska reneta i Siva francuska reneta. Vrlo dobrom kvalitetom odlikuju se (od 150 -170), se sorte: Blenheimska, Mašanka, Ljepocvjetka, Zlatna zimska parmenka, Crvena jesenska rebrača, Jonathan, Kaselska reneta i Golden Delicious. 


\section{LITERATURA}

ASIRELLI A., SANSAVINI S., BALDASSARI M. T., PIAZZA R., (1997.): Un' indagine al mercato ortofrutticole di Bologna: il qualità percepibile delle mele di pianura e di montagna. Atti del „Convegno Melicoltura di pianura: quale futuro“, Verona 12 aprile 1997., 65-88.

COMAI M., CORRADINI F., PORRO D., FAILlA O., (1995.): Effect of nitrogen supply in herbicide strips, or in grass on apple growth, yield and fruit quality, Mineral nutrition of deciduous fruit plants, Trento, Italy, Sept. 13-17, 1993. Acta Hort. 451, 279-285.

FALLAHI E., RICHARDSON D. G., WESTWOOD M. N., (1985.): Quality of apple frit a high density orchards as influenced by rootstocks, fertilizers, maturity, and storage, J. Amer. Soc. Hort. Sci. 110 (1): 149-153.

FOROSITH F. R., WEBSTER D. H., (1970.): Volatiles from McIntosh apple fruits as affected by phosphorous and potassium nutrition. J. Amer. Soc. Hort. Sci., 96 (3), 259-263.

GORINI F., (1986.): Relazione fra fertilizzazione qualità e conservabilità, Atti del Convegno „La fertilizzazione delle piante da frutto“, Verona 21 marzo 1986.

GULIANI R., NEROZZI F., MAGNANINI E., CORELLI-GRAPPADELLI L., (1997.): Influence of environmental and plant factors on canopy photosynthesis and transplantation of apple trees. Tree Physiology, 17 810), 637-645.

HÖLLER I., GUERRA W., (2009.): Gusti e sapori delle mele - Ciascun Paese ha le sue preferenze!, Frutta e Vite 33 (3): 122-125.

LEE C. Y., (2012.): Common Nutrient and Nutraceutical Quality of Apples, New York Fruit Quarterly Volume 20: 3-7

MILJKOVIĆ I., (2918.): Istraživanje kemijskog sastava i kvalitete plodova jabuke na M podlogama. Pomologia Croatica, Vol. 22, br. 1-2: 95-108.

MILJKOVIĆ I., (2018.): Istraživanje utjecaja klimatskih prilika na kemijski sastav i kvalitetu plodova sorti jabuke u Hrvatskoj. Zbornik sažetaka 11. Međunarodnog kongresa Oplemenjivanje bilja, sjemenarstvo i rasadničarstvo, Umag, 2018.

MILJKOVIĆ I., (2021.): Jabuka, str. 1-1000, Naklada autora, Zagreb. 
NOE N., ECCHER T., PORRO D., STAINER R., (1997.): Quality of Golden Delicious apples as affected by season and by nitrogen and potassium mineral nutrition. Acta Hort. 448, 487-497.

SANSAVINI S., MUSACCHI S., VENTURA M., ASIRELLI A., (1999.): I portinnesti del melo. Supplemento a L'Informatore Agrario 6: 25-31.

SANSAVINI S., CORELLI GRAPPADELLI L., ECKER T., NOE N., PORRO D., (1990.): Frutti ecologici e qualità delle mele; Frutticoltura, 12: 78-81.

SANSAVINI S. et al. (2002.): I portinnesti del melo, Supplemento a L'Informatore Agrario 51: 17-25

STEINER R., STEFANELLI D., LANZIONI S., PELLEGRINO S., SANSAVINI S., (2000.): Valutazione sensoriale e strumentale di melo di diversa provenienza. Frutticoltura (7/8): 53-62.

ŠTAMPAR K., (1952.): Odnos šećera i refraktometrijske vrijednosti kod voća. Poljoprivredna znanstvena smotra br. 13: 155-168.

WATADA A. E., ABBOTT J. A., J. A. HARDENBURG R. E., (1980.): Sensory characteristics of apple fruit. Jur. Amer, Soc. Hort. Sci. 105: 371- 375.

\section{Adresa autora - Author's address}

Prof.dr.sc. Ivo Miljković, e-mail: ivo.miljkovic@yahoo.com Čazmanska 2, 10000 Zagreb 